\title{
Emancipación tecnológica en el sector biomédico
}

\author{
Natali Olaya Mira ${ }^{1}$
} ${ }^{1}$ M.Sc. Ingeniería Mecánica. Bioingeniera, Facultad de ciencias exactas y apli-
cadas Instituto Tecnológico Metropolitano Medellín, Colombia.
Email: natali.olaya@itm.edu.co
色 OPEN ACCESS

\section{(C) $(1) \Theta$}

\section{Copyright:}

(02020. La revista Ingenierías USBmed proporciona acceso abierto a todos sus contenidos bajo los términos de la licencia creative commons Atribución no comercial SinDerivar 4.0 Internacional (CC BY-NC-ND 4.0)

Editor: Andrés Felipe Hernández. Universidad de San Buenaventura, Medellín, Colombia.
La aparición del virus COVID-19 ha impuesto una nueva situación mundial en todas las esferas de intervención humana. No obstante, en medio de la vorágine de estos cambios inexorables surge la oportunidad de aplicar los conocimientos científicos al manejo de la crisis, que es la finalidad de la ingeniería en su definición más sencilla.

Aunque la crisis sea generalizada, es en el sector salud donde se visibiliza con más fuerza. Por lo tanto, es allí donde puede actuar la ingeniería biomédica, que orienta sus desarrollos hacia la solución de problemas relacionados con la salud humana, y en este caso, con la escasez de equipamiento e infraestructura hospitalaria.

Así fue como surgieron iniciativas en todo el país para el diseño y construcción de ventiladores mecánicos de bajo costo y todo tipo de dispositivos, con el fin de ayudar al sector salud, al que se unió la academia, la industria y el Estado. Muchas de estas propuestas exitosas y llevadas a cabalidad con todos los requisitos científicos y legales, han demostrado que gracias a la sinergia y voluntad de estos actores es posible vislumbrar una independencia tecnológica en la fabricación de dispositivos médicos en el país. Se tiene el capital humano, la trayectoria académica, las herramientas y la experiencia industrial, elementos que junto a la intención y los recursos del gobierno podrían conducirnos a ser autosuficientes a largo plazo en cuanto a tecnología biomédica en Colombia. 